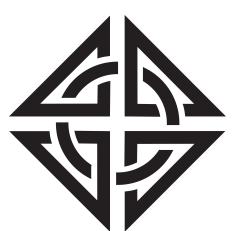

SCIENTIA

I RA N I C A
Sharif University of Technology

Scientia Iranica

Transactions A: Civil Engineering

http://scientiairanica.sharif.edu

\title{
Predicting the collapsibility potential of unsaturated soils using adaptive neural fuzzy inference system and particle swarm optimization
}

\author{
M.M. Hasheminejad*, N. Sohankar, and A. Hajiannia \\ Department of Civil Engineering, Najafabad Branch, Islamic Azad University, Najafabad, Iran.
}

Received 8 June 2016; received in revised form 17 February 2017; accepted 5 February 2018

\author{
KEYWORDS \\ Collapsibility \\ potential; \\ Soft computing; \\ Adaptive neural fuzzy \\ inference system; \\ Particle swarm \\ optimization; \\ Gaussian membership \\ function.
}

\begin{abstract}
Soil collapsibility is one of the important phenomena in unsaturated soil mechanics. This phenomenon can impose extensive financial damages on civil engineering structures due to soil subsidence. Because of uncertainties in effective parameters and their measurements, no precise mathematical relation has been proposed for collapsibility potential evaluation. Therefore, soft computing techniques, such as fuzzy logic, could be a suitable choice to account for different factors. Adaptive Neural Fuzzy Inference System (ANFIS) was used in this study. To predict the collapsibility potential, hybrid algorithm and Particles Swarm Optimization (PSO) were employed by ANFIS for system training. Gaussian membership functions were utilized for fuzzifying the data. In addition, data classification was performed in a subtractive form in the fuzzy inference system. A total of 327 laboratory data were used in the particle swarm algorithm, 266 of which were chosen for training and 66 for testing. The obtained results showed the effects of different parameters and the rate of their changes in collapsibility potential. Moreover, the comparison of different approaches of system training was done using a correlation coefficient. The superiority of the proposed method and the utilized techniques was shown by comparing the results with the ones obtained by other researches.

(C) 2018 Sharif University of Technology. All rights reserved.
\end{abstract}

\section{Introduction}

One of the primary actions in executing a civil project is considering geology and soil conditions in its place. Generally, any soil mass affected by load is deformed and settled. Type and rate of deformation depend on different factors and conditions, such as the type of structure, environmental conditions, loading, and soil properties, such as compaction, humidity, etc. These

*. Corresponding author. Tel.: +983136688444 E-mail addresses: m.m.hasheminejad@gmail.com (M.M. Hasheminejad); sohankar.n@gmail.com (N. Sohankar); alborzhn@yahoo.com (A.Hajiannia).

doi: $10.24200 /$ sci. 2018.20176 factors affect the design and construction in completing a safe and economic project. Many structures are built on unsaturated soils with the possibility of getting saturated environmentally. Thus, one of the most important phenomena occurring in such conditions is soil collapsibility. The widespread existence of unsaturated soils and the construction of structures, such as dams and irrigation canals, on these soils reveals the importance of the study in this field. In addition, the extension of urbanism and industries, placement of water and sewerage lines on these soils, and insertion of their sewerages in soil media can highlight the necessity and urgency of considering the point [1]. Collapsibility potential was introduced first by Jennings and Knight [2]. Various criteria have been considered by many researchers to predict the soil 
collapsibility. One of the primary criteria was presented by Clevenger, who only considered the effects of dry unit weight [3]. The other criterion was considered by Gibbs and Bara, who employed dry unit weight and liquid limit to separate collapsible and non-collapsible soils [4]. Denisov investigated the ratio of soil natural porosity to soil porosity during liquid conditions as a controlling parameter [5]. Fookes and Best also used a collapsibility index that was the ratio of the difference of natural and critical porosity to difference of soil porosity in liquid and plastic limits [6]. The principles dominating saturated soil are adequately extended, both theoretically and practically, and the mechanical behavior of these soils is a function of an effective stress principle [7]; however, considering this principle for unsaturated soils has been only successful to a limited extent that requires more studies and attentions [8,9]. Since the collapsibility phenomenon occurs in these soils, the necessity of doing numerical researches is revealed in accordance with the unsaturated soil mechanics theory. Attempts have been made in the late 1980 s to provide mathematical and computer models to analyze unsaturated collapsible soil behaviors. For instance, Amirsoleimani (1988) presented a mathematical model with regard to soil stability and statistical principles. Moreover, Haydari (1990) analyzed the lateral compression effects on the behaviors of collapsible soil by presenting a mathematical model. DeBon et al. (1998) published the results of their researches regarding the behavioral model of collapsible soil by Monte Carlo analysis. Another method of modeling considered in the past few decades was the use of soft computing in civil engineering. For example, the work of Khademi et al. (2016) presented prediction result of concrete compressive strength using artificial neural network modeling [10]; Zorlu and Gokceoglu (2008) dealt with predicting the collapsibility index using a double input fuzzy inference system in the Mamdani method [11]; the activities by Momeni et al. (2011) focused on predicting soil collapsibility potential using the fuzzy system [12]. Kang and $\mathrm{Li}$ published Artificial bee colony algorithm optimized support vector regression for system reliability analysis of slopes [13]. The other work done in this regard was carried out by Basma and Tuncer, who presented formulas according to the data from laboratory test experiments and regression analysis [14]. The accuracy of these relations was evaluated by Habib-agahi and Taherian who utilized neural networks [15].

In recent years, the PSO method has been used for many researches in geotechnical engineering. For instance, Zhang et al. presented an elasto-plastic model of unsaturated soils by using the PSO [16]. Moreover, Saeedi et al. determined the critical failure surface in the homogeneous slopes by using the PSO [17].
Jalalvandi and Kashani published the design of reinforcement length in reinforced slope using the PSO [18]. Kang et al. published slope reliability analysis using surrogate models via new support vector machines with swarm intelligence [19] and published system reliability analysis of slopes using the least squares support vector machines with particle swarm optimization [20].

ANFIS and PSO were used in this study to predict soil collapsibility potential. The data were obtained using experimental studies in the literature [15]. The sensitivity of different parameters in predicting collapsibility potential was evaluated. The advantage of using this method, as compared to the previous ones, was its higher precision. Moreover, the probability of trapping in a local minimum was comparatively low. Moreover, it was shown that the stability of the utilized technique was enough with respect to other approaches, which results in more accurate simulated answers.

\section{Collapsible soil}

Collapsible soils are unsaturated soils that undergo a sudden and intense reduction in volume during saturation. An unsaturated and porous structure, stress applied to soil, a cementation factor causing soil stability in the unsaturated state, and the humidity causing the reduction of adhesion between the particles are required for collapsibility [21]. The e-logp curve is used to describe the behavior of collapsible soil, as shown in Figure 1.

The "ab" curve is obtained by consolidation test on the soil sample in natural humidity, and the void ratio is equal to " $e_{1}$ " in the pressure of " $P_{w}$ ". If the soil is saturated at this point, it collapses. In other words, the collapsing process is a rearrangement of soil particles transformed from the loose state to the compacted one. Curve "bc" indicates that soil, after saturation, collapses under constant pressure, and its void ratio is " $e_{2}$ " at the constant pressure of " $P_{w}$ "; however, $e_{2}<e_{1}$. "cd" curve shows that the soil is influenced by the extra load after saturation. The specific properties of collapsible soils are their high void ratio, low dry unit weight, and zero or negligible adhesion. There are different factors affecting collapsible potentials, some of which are seen in Table 1.

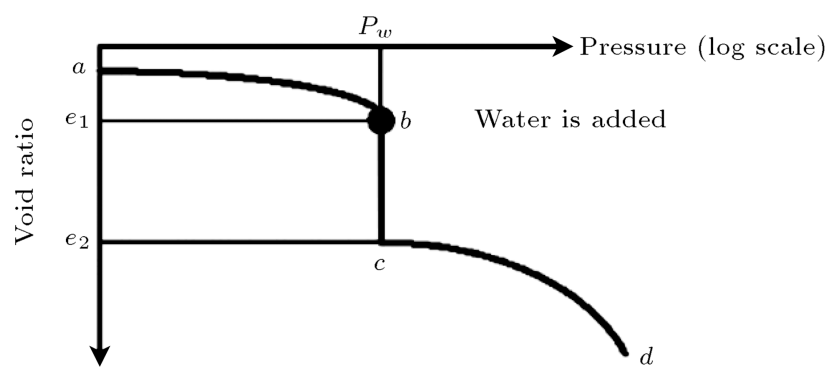

Figure 1. Void ratio-pressure curve of collapsible soil. 
Table 1. Effective factors in collapsible potential.

\begin{tabular}{cc}
\hline $\begin{array}{c}\text { Input variables } \\
\text { (effective factors }\end{array}$ & Output variable \\
in collapsible potential) & \\
\hline Dry unit weight & \\
Moisture content & \\
Applied pressure & Collapsible \\
Clay percentage & Potential \\
Silt percentage & $(\mathrm{CP})$ \\
Uniformity coefficient & \\
Soil plastic parameters & \\
(liquid limit, etc.) & \\
\hline
\end{tabular}

Natural soil as well as compacted soil in embankments, etc. can be easily subject to collapsibility. Consolidation test on the soil sample is used to obtain collapsibility potential, as introduced by Jennings and Knight [2]. The sample is placed for this test in the consolidation test ring and load is increased in steps up to the pressure of about $200 \mathrm{kgN} / \mathrm{m}^{2}$. In this pressure $\left(P_{w}\right)$, the sample is saturated and left for 24 hours. Thus, the void ratio, before and after saturation, can be measured. Finally, the collapsibility potential can be calculated by the following formula.

$$
C P=\frac{\left(e_{1}-e_{2}\right)}{1+e_{0}} \text {. }
$$

$e_{1}$ and $e_{2}$ indicate the sample void ratio before and after saturation, and $e_{0}$ is the initial void ratio of soil in the natural state.

\section{Adaptive neural-fuzzy inference system}

ANFIS (Adaptive Neural-Fuzzy Inference System) is a combination of neural networks and fuzzy logic. ANFIS can serve as a basis for the construction of a set of fuzzy if-then rules with appropriate membership functions to generate the stipulated input-output pairs $[22,23]$. In other words, ANFIS is identified as a universal estimator for responding to complex problems. ANFIS is a class of adaptive, multi-layer and feed-forward networks comprised of input-output variables and a fuzzy rule base of the Takagi-Sugeno type [24]. The ambiguities in a problem could be rooted in various reasons, including complexity of the problem or lack of adequate information or our inability to have precise measurements. Thus, it can be noted that the type of existing uncertainty in a problem is a very important point for engineers who should first think about it in order to select a proper way in expressing the ambiguities. One of the existing methods for expressing some of the ambiguities is fuzzy logic. A fuzzy set includes members that express inaccurate characteristics of the membership. Many fuzzy membership functions could be defined, the most applicable of which are triangular,

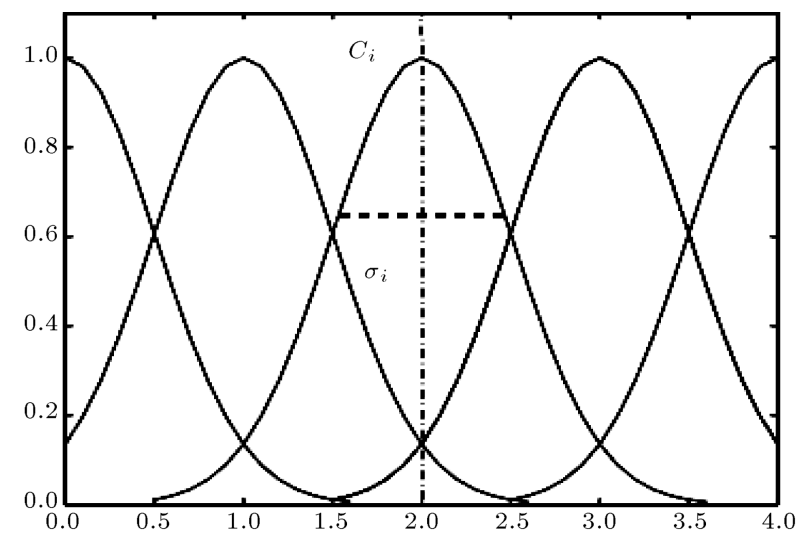

Figure 2. Fuzzy membership functions.
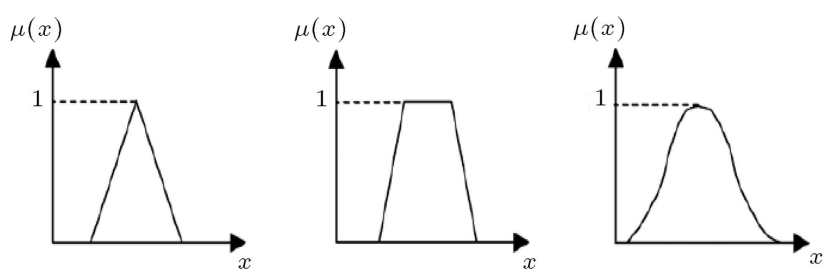

Figure 3. Fuzzy membership functions.

trapezoidal, bell and Gaussian membership functions, as shown in Figures 2 and 3.

The difference between a fuzzy set and a classic one is that we have one membership function in the latter, while there are many membership functions in the former. The members in the classical set are mapped in 0,1 , yet also mapped in $[0,1]$ space for the fuzzy sets, as shown in Figure 3 .

The main advantage of using fuzzy system could be using human's experiences and knowledge and transforming them into the numerical form. In other words, transforming linguistic variables into the quantitative form is the most important feature of it. The other advantage is that it is used as a new tool for solving ambiguities that cannot be done by the probability theory. A Fuzzy Inference System (FIS) is shown in Figure 4.

The relations between inputs and outputs are considered by a set of rules in the form of "IF-THEN". The written rules are called "rule-based" ones. Fuzzy rule-based modeling is a qualitative modeling scheme based on which the system behavior is described using

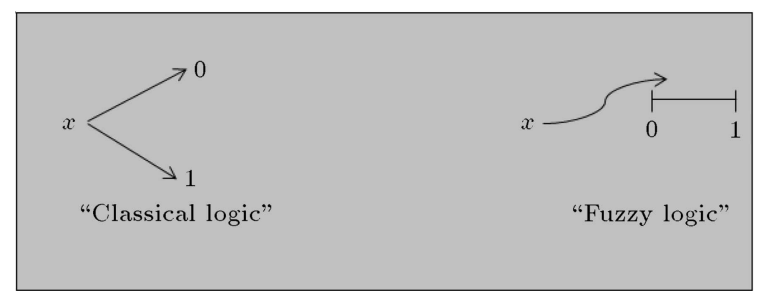

Figure 4. The difference between the fuzzy logic and the classical logic. 
natural language [25], and its general form is as follows:

- Rule: If $x$ is $A$, then $y$ is $B$.

where $x$ and $y$ are variables, and $A$ and $B$ are defined fuzzy sets on the variables $x$ and $y$. Moreover, inferring from the rules in this step, decisions are made on the written rules according to intersection, union, and complement operators that are in conformity with "and", "or", and "no", respectively.

The most applicable models include the Mamdani fuzzy approach and (Takagi-Sugeno-Kang) "TSK". The main difference between the above two models is that human's experience is used in the Mamdani model for designing fuzzy membership functions and writing the rules; however, optimization techniques and adaptive methods are employed in the Takagi-SugenoKang model. The number of written rules in TakagiSugeno-Kang model is less than that in the Mamdani model. Thus, Takagi-Sugeno-Kang model is used and preferred more than Mamdani model [26].

The neural-fuzzy inference system is obtained by combining the fuzzy logic with the neural network. A neural network is a data-oriented system working only according to the data and has no possibility of having access to experimental information and human's knowledge. Thus, by combining that with the fuzzy logic, a strong tool can be created in order to transform qualitative information into quantitative data and use them for engineering works without heavy numerical calculations. This system can be applied to interpolation, modeling, identification of dynamic system, prediction, etc. A Takagi-Sugeno-Kang model is used in ANFIS, where the output of the rules is in the linear form of inputs of the same rules. The final output is the weighted average of the output of the rules obtained by the collection of outputs. An adaptive neural-fuzzy inference is shown in Figures 5 to 7 , with two inputs and two rules:

- Rule 1: If $x$ is $A_{1}$ and $y$ is $B_{1}$, then $f_{1}=p_{1}^{*} x+q_{1}^{*} y+$ $r_{1}$

- Rule 2: If $x$ is $A_{2}$ and $y$ is $B_{2}$, then $f_{2}=p_{2}^{*} x+q_{2}^{*} y+$ $r_{2}$,

where $A_{1}$ and $A_{2}$ are fuzzy membership functions for inputs $x$ and $y$, and coefficients $r_{1}, r_{2}, q_{1}, q_{2}, p_{1}, p_{2}$ are parameters to be determined.

The first layer is the fuzzification step, and the Gussian membership function is usually used in this structure.

Weight coefficients, defined in the second layer, are calculated from the following relation.

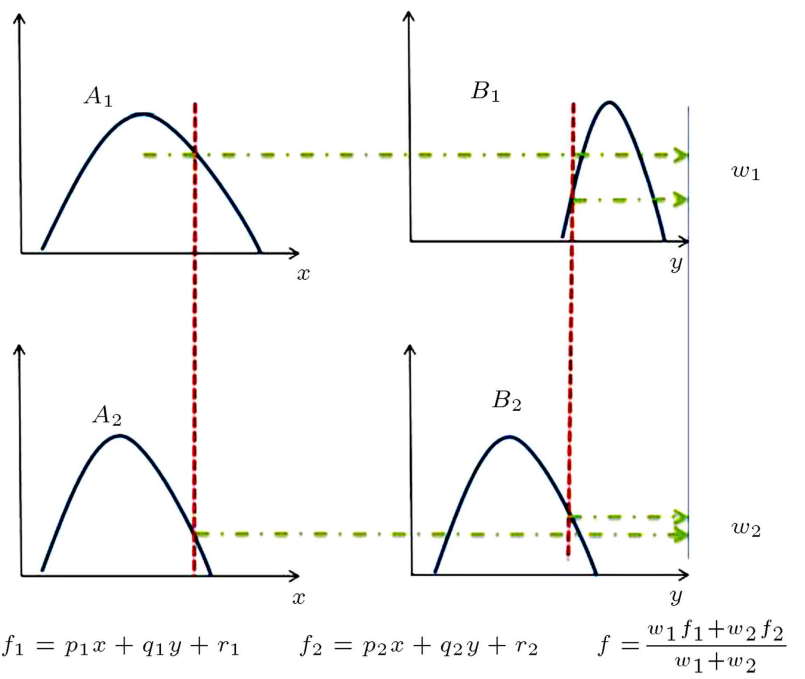

Figure 6. Sugeno-type 1 model structure.

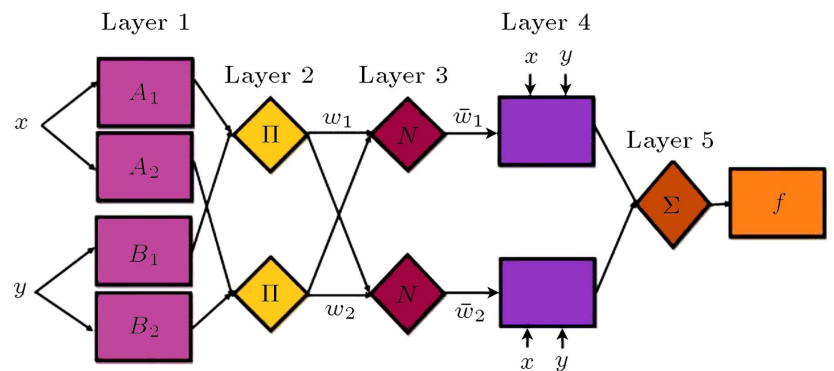

Figure 7. Adaptive neural fuzzy inference system structure [24].

$$
w_{i}=\mu A_{i}(x) \cdot \mu B_{i}(y), \quad i=1,2 .
$$

Weight coefficients are normalized in the third layer, and the following relation is used in this regard:

$$
\bar{w}_{i}=\frac{w_{i}}{w_{1}+w_{2}}, \quad i=1,2 .
$$

Normalized weight coefficients in the fourth layer are multiplied by the output of each rule.

$$
\bar{w}_{i} f_{i}=\bar{w}_{i}\left(p_{x}+q_{i} y+r_{i}\right) .
$$

The total of outputs in the fifth layer is considered as the final output.

$$
\sum \bar{w}_{i} f_{i}=\frac{\sum w_{i} f_{i}}{\sum w_{i}} .
$$

\subsection{Clustering}

Clustering the numerical data is the basis of many clustering algorithms and systems modeling. The aim of this work is grouping very large data and providing

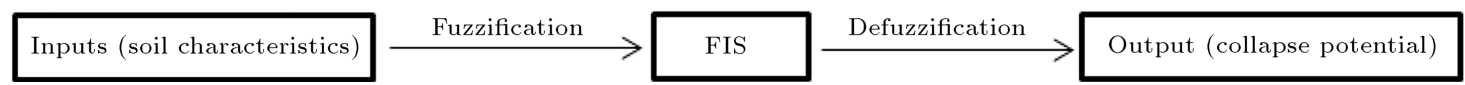

Figure 5. Fuzzy inference system structure. 
a simple indication of the system behavior. There are different methods for determining the primary model structure of fuzzy inference system, among which grid partition and Subtractive Clustering Method (SCM) can be named in this regard. The subtractive clustering method has been used in this study. The task of this clustering is to consider random points as the cluster centers. Then, the distances of every data from the centers are calculated. The data are related to the group with the shortest distance from its center. In other words, the groups compete with each other for dominating the data in accordance with the distance from the center to the data. Then, after the first round, the group center is modified. For instance, the mean of the data related to a group is considered as the new center of the cluster. It continues up to getting very low difference of the new center to the previous one. An effective radius is defined in subtractive clustering, and the data in that radius are considered as the group member. In other words, " $m$ " points of the data are selected as the center in subtractive clustering. Then, the potential of each point, such as " $z_{i}$ ", is calculated from the following relation:

$$
D_{i}=\sum \exp \left(\frac{-\left\|\left(z_{i}-z_{j}\right)\right\|^{2}}{\left(\frac{r}{2}\right)^{2}}\right)
$$

where " $r$ " is the effective radius that has a positive and fixed value.

After the calculation of the potential for each point, the point with the highest potential is selected as the first cluster center. The value for the potential is the function of distance from other points. Potential values of other points are calculated from the following relation:

$$
\left(D_{i}\right)_{\text {new }}=D_{i}-D_{c 1} * \sum \exp \left(\frac{-\|\left(z_{i}-z_{c 1} \|^{2}\right.}{\left(\frac{r}{2}\right)^{2}}\right),
$$

where $D_{c 1}$ and $z_{c 1}$ are determined from the previous step and, similar to that step, $z_{c 2}$ cluster center is determined. This process continues until when the number of required clusters is determined.

\subsection{Hybrid algorithm and particles swarm}

Hybrid algorithms and particles swarm are both among optimizing methods. Several evolutionary methods can be applied to solve optimization problems. Among the available solution technique, PSO is proved to be robust, effective and easy to apply [27]. Hybrid algorithm is performed according to the two methods of the least squares errors and gradient descent-backward pass, and particles swarm acts according to random search. Particles swarm algorithm is inspired by the social behavior of birds or fish in finding their food. It is assumed in this algorithm that a group of birds are looking for food in a random way in a region, while only one part of the region has food to find. The used strategy is that the birds are following a bird nearest to the food. In particles swarm algorithm, each response to the question is a bird in the searching space, called a particle, as these birds are in the searching area that we intend to quantify (optimize). Each particle calculates the target function in its spatial situation. Then, by using the combination of information, the bird selects its present location, the best place where it was before and the information regarding one or more particles for the direction of moving, as other birds have done. After a move, a stage of the algorithm ends. In fact, particles move in the responding space, and the obtained results are calculated according to competence criteria. Particles go towards the ones with more competence. The main advantage of this method is that the large number of particles causes flexibility of the method against the problem of optimized local response, with a rather proper speed in convergence. In the algorithm of particles swarm, each member has its own specific speed to move accordingly and a memory to remember the best place they reach. The particles' behaviors in each iteration are affected by other particles', and a coordination is created between all particles, causing each to move towards the best response it has so far found; secondly, each particle moves towards the best response that others have reached. If the searching space has $D$ dimensions, then the $i$ th particle can be shown with a $d$-dimensional vector as $x_{i}=\left(x_{i 1}, x_{i 2}, \ldots, x_{i D}\right)$ that indicates the particle situation; in addition, by a velocity vector, it is shown as $v_{i}=\left(v_{i 1}, v_{i 2}, \ldots, v_{i D}\right)$. The place and velocity of particles are modified according to the following relations [28]:

$$
\begin{aligned}
v_{i}\{k+1\}= & v_{i}\{k\}+c_{1} r_{1}\left\{x_{p i}-x_{i}\{k\}\right\} \\
& +c_{2} r_{2}\left(x_{G}-x_{i}\{k\}\right), \\
x_{i}\{k+1\}= & x_{i}\{k\}+v_{i}\{k+1\},
\end{aligned}
$$

where $x_{p i}$ is the best situation the particle has so far obtained, and $x_{G}$ is the best situation the particle has reached among the rest of the population. Fixed positive coefficients that are indeed accelerating coefficients towards the optimized points are defined by $c_{1}$ (cognitive parameter) and $c_{2}$ (social parameter).

\subsection{Data}

The applied data include a set of data obtained from laboratory tests results from the paper by Habibagahi and Taherian [15] and a set of data by Basma and Tuncer (1992) [14]. A total of 327 data were used, 261 of which were for training and 66 for testing. The data and their features can be observed in Appendix (A). 


\section{Summary and results}

The Adaptive Neural Fuzzy Inference System (ANFIS) and particles swarm algorithm were used in this study to estimate the collapsibility potential for soils. The data by Habibagahi and Taherian and Basma and Tuncer were employed for this purpose. The main aim of this study was the analysis of the described methods and comparison of them with the methods presented by other researchers. For this purpose, $R$ square was used. $R$-square is a statistical method that explains how much the variability of a factor can be affected or explained by its relationship to another factor. It is computed as a value between 0 and 1 . The higher the value, the better the fit. It is symbolized by $R^{2}$ and is an important tool in determining the degree of the linear correlation of variables in regression analysis. Tables 2 and 3 show the comparisons between different methods; membership functions are shown in Figures 8-14; the relationship between input variables and collapsible potential is shown in Figures 15-19.

Increasing elements such as dry unit weight, liquid limit, and clay percentage caused the reduction of collapsibility potential, and increasing silt percentage enhanced collapsibility potential. These results are in conformity with those obtained by Habibagahi and

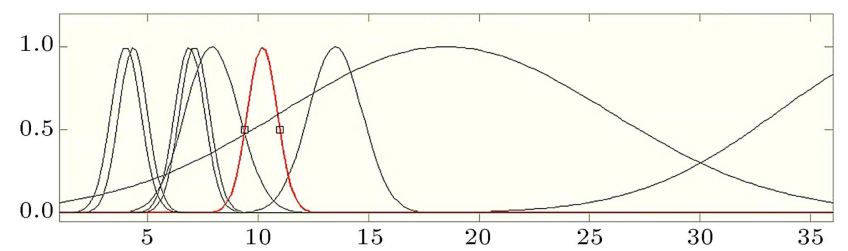

Figure 8. pressure at wetting $(100-3600 \mathrm{kPa})$.

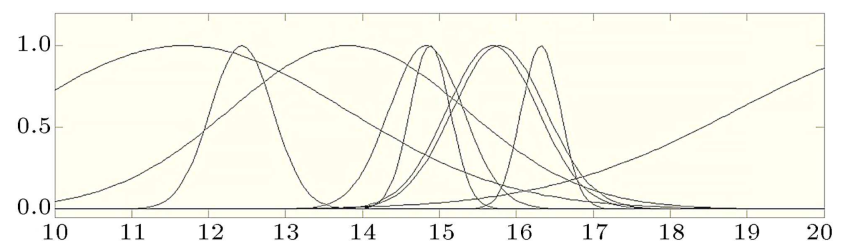

Figure 9. Fuzzy membership function-dry unit weight $\left(11.4-19.3 \mathrm{kN} / \mathrm{m}^{3}\right)$.

Table 2. Comparison between ANFIS and PSO.

\begin{tabular}{cccccc}
\hline & \multicolumn{2}{c}{ ANFIS } & & \multicolumn{2}{c}{ PSO } \\
\cline { 2 - 3 } \cline { 5 - 6 } & Training & Testing & & Training & Testing \\
\hline $\boldsymbol{R}$ & 0.98252 & 0.94659 & & 0.98462 & 0.95678 \\
$\boldsymbol{R}^{\mathbf{2}}$ & 0.9850 & 0.9533 & & $\mathbf{0 . 9 8 6 8}$ & $\mathbf{0 . 9 6 3 2}$ \\
\hline
\end{tabular}

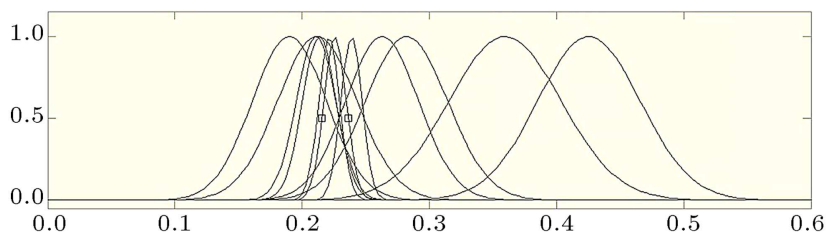

Figure 10. Fuzzy membership function-liquid limit $(0-57.2 \%)$.

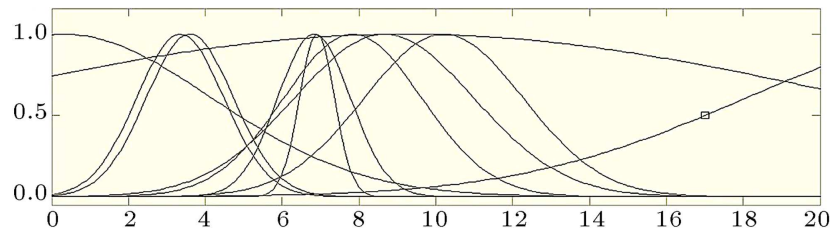

Figure 11. Fuzzy membership function-water content (0-20\%).

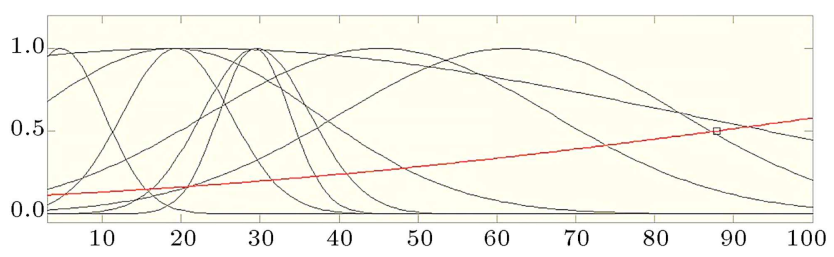

Figure 12. Fuzzy membership function-Cu (3.4-100\%).

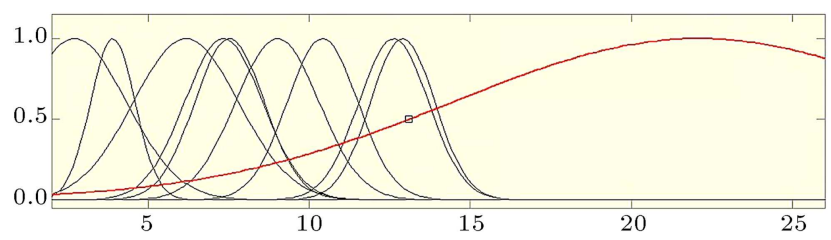

Figure 13. Fuzzy membership function-clay (2-26\%).

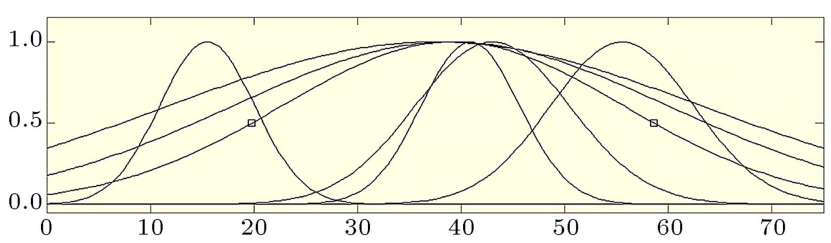

Figure 14. Fuzzy membership function-silt (5.8-75\%).

Taherian. Moreover, the rate of effectiveness of dry unit weight was higher than that of other factors in collapsibility of soil. By comparing Tables 2 and 3, it can be seen that the performance of the studied methods in this study yielded better results, and the particles swarm algorithm had the best performance among others. Table 4 shows the rate of changes of the results relative to those obtained by Habibagahi and Taherian [15].

Table 3. Various neural network results.

\begin{tabular}{ccccccccc}
\hline & \multicolumn{2}{c}{ BPNN } & & \multicolumn{2}{c}{ RNN } & & \multicolumn{2}{c}{ GRNN } \\
\cline { 2 - 3 } & Training & Testing & & Training & Testing & & Training & Testing \\
\hline $\boldsymbol{R}^{\mathbf{2}}$ & 0.97 & 0.95 & & 0.96 & 0.93 & & 0.98 \\
\hline
\end{tabular}


Table 4. Rate $R^{2}$ changes.

\begin{tabular}{|c|c|c|c|c|c|c|}
\hline & \multicolumn{2}{|c|}{ BPNN } & \multicolumn{2}{|c|}{ RNN } & \multicolumn{2}{|c|}{ GRNN } \\
\hline & Training & Testing & Training & Testing & Training & Testing \\
\hline ANFIS & 1.55 & 0.35 & 2.6 & 2.5 & 0.51 & 3.62 \\
\hline PSO & 1.73 & 1.39 & 2.8 & 3.57 & 0.69 & 4.7 \\
\hline
\end{tabular}

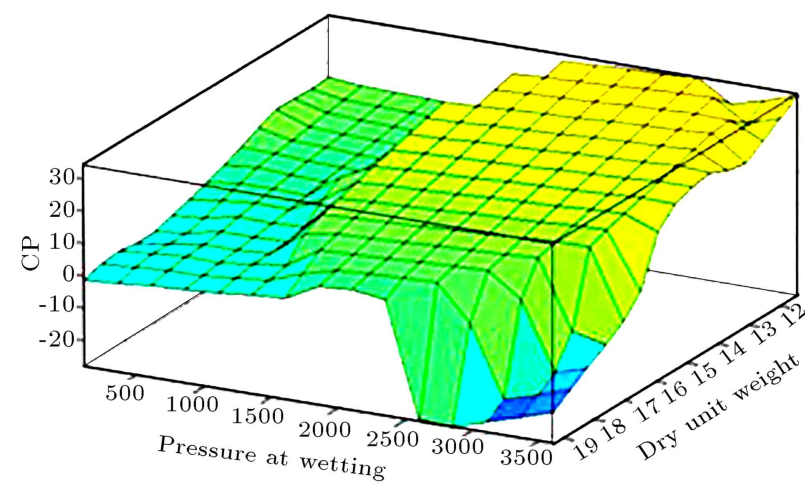

Figure 15. CP-pressure at wetting-dry unit weight.

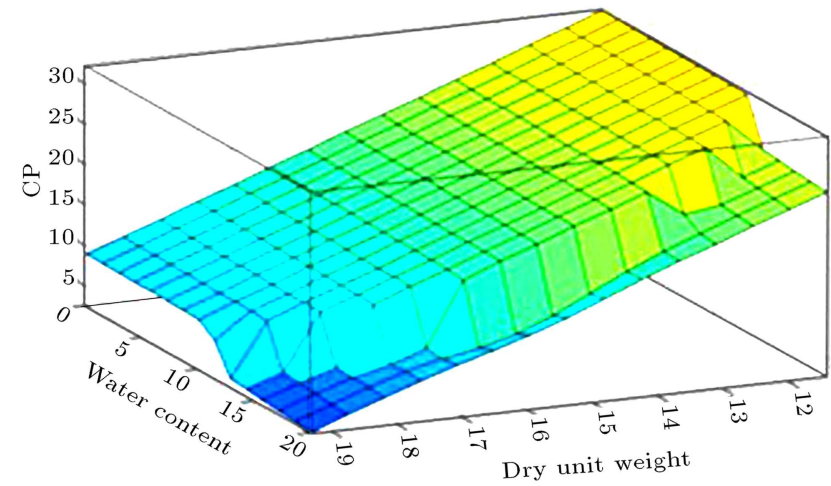

Figure 16. CP-unit dry weight water content.

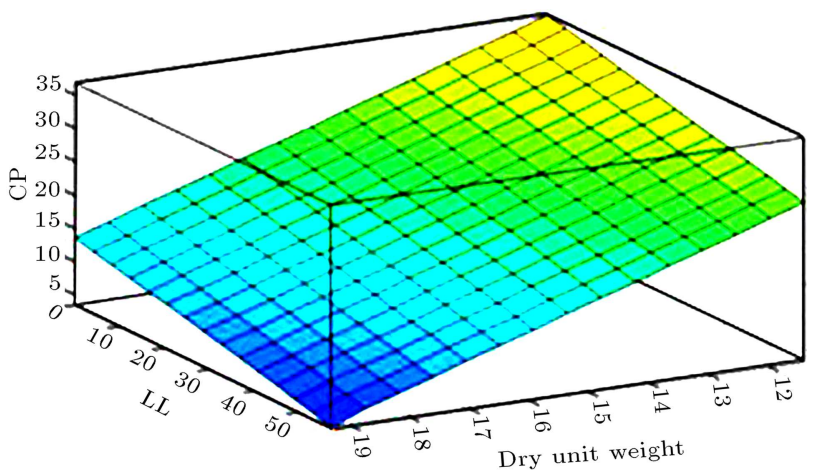

Figure 17. CP-LL dry unit weight.

\section{Conclusion}

This paper investigated collapsible potential in unsaturated soils numerically using ANFIS in this paper. Techniques of hybrid algorithm and PSO were employed by this method for system training. By the way, Gaussian membership functions were utilized for fuzzifying the experimental data. This combining approach

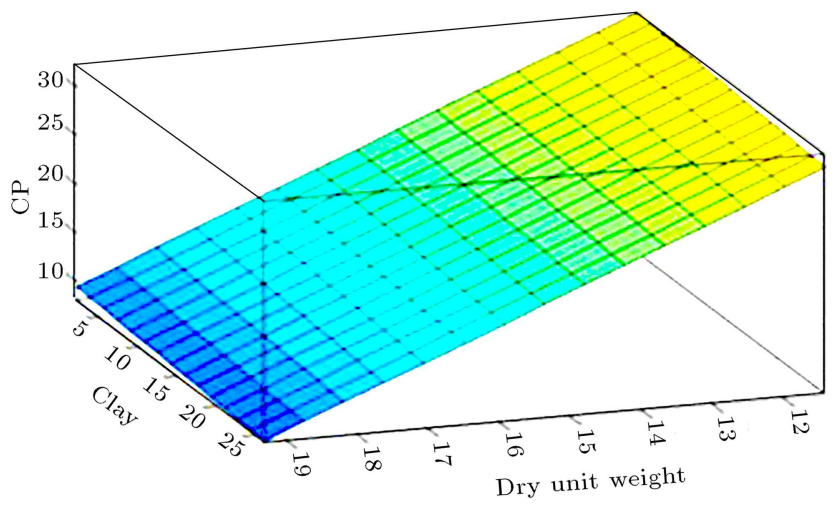

Figure 18. CP-clay dry unit weight.

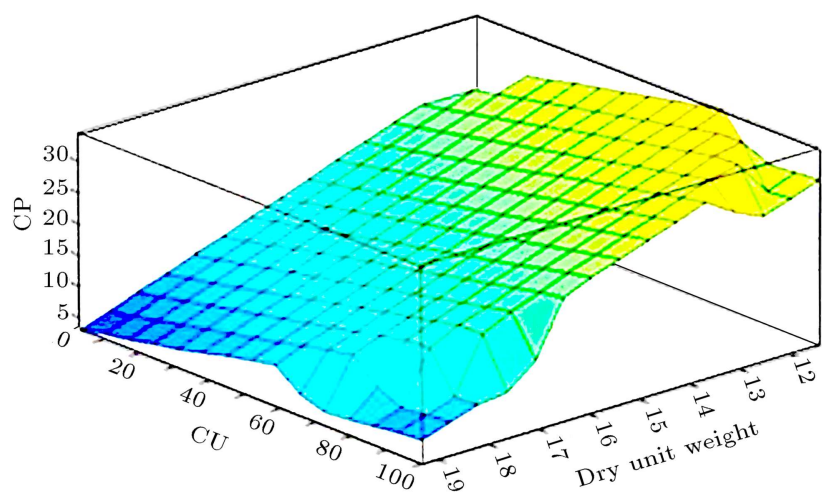

Figure 19. CP-Cu dry unit weight.

can predict the collapsibility potential of unsaturated soils more accurately. The advantage of the utilized method rather than other approaches is the stability of the results. In addition to the observation upon which the results of the presented methods were in conformity with the obtained results, with acceptable correlations, they had a better performance in comparison to the methods suggested by other researchers. Moreover, using the PSO algorithm, instead of classical ways, in the hybrid algorithm showed considerable results. It was also revealed that this method could be a strong tool in predicting the potential for soil collapsibility, while conducting it by laboratory tests is a difficult work.

\section{References}

1. Derbyshi, E. "Geological hazards in loess terrains whit particular reference to the loes regions of china", Earth-science, Reviews, 54, pp. 31-60 (2001).

2. Jennings, J.E. and Knight, K. "A guide to construction on or with materials exhibiting additional settlements 
due to collapse of grain structure", Proceedings, Sixth Regional Conference for Africa on Soil Mechanics and Foundation Engineering, Johannesburg, pp. 99-105 (1975).

3. Clevenger, W.A. "Experiences with loess as a foundation material", Transactions American Society for Civil Engineers, 123, pp. 51-80 (1959).

4. Gibbs, H.J. and Bara, J.P. "Predicting surface subsidence from basic soil test", A.S.T.M. Spec. Teach. Pub., 322, pp. 231-246 (1962).

5. Denisov, N.Y. "About the nature of high sensitivity of quick clays", Osnov. Fudam. Mekh. Grunt, 5, pp. 5-8 (1964).

6. Fookes, P.G. and Best, R. "Consolidation characteristics of some late Pleistocene periodical metastable soils of east Kent". Quarterly Journal of Engineering Geology, 2, pp. 103-128 (1969).

7. Terzaghi, K., Theoretical Soil Mechanics, Wiley, New York (1943).

8. Bishop, A.W., Alpan, I., Blight, G.E., and Donald, I.B. "Factors controlling the shear strength of cohesive soils", Proc., ASCE Res. Conf., New York, pp. 503-532 (1960).

9. Burland, J.E. "Effective stresses in partly saturated soils discussion on some aspects of effective stresses in saturated and partly saturated soils by G.E. Blight and A.W. Bishop", Geotechnique, London, 14, pp. 6568 (1964).

10. Khademi, F., Akbari, M., and Jamal, S.M. "Prediction of concrete compressive strength using ultrasonic pulse velocity test and artificial neural network modeling", Revista Romana de Materiale, 46(3), p. 343 (2016)

11. Zorlu, K. and Gokceoglu, C. "Prediction of the collapse index by a Mamdani fuzzy inference system", In: Lovrek, I., Howlett, R.J., and Jain, L.C. (Eds.) Knowledge-Based Intelligent Information and Engineering Systems, KES, Lecture Notes in Computer Science, 5177, Springer, Berlin (2008)

12. Momeni, M., Shafiee, A., Heidari, M., Jafari, M.K., and Mahdavifar, M.R. "Application of fuzzy set theory in evaluation of soil collapse potential", IJST, Transactions of Civil Engineering, 35(C2), pp. 271-275 (2011)

13. Kang, F. and Li, J. "Artificial bee colony algorithm optimized support vector regression for system reliability analysis of slopes", Journal of Computing in Civil Engineering, 30(3), pp. 41-54 (2016).

14. Basma, A.A. and Tuncer, E.R. "Evaluation and control of collapsible soils", J. Geotech. Engrg. Asce, 118(10), pp. 1491-1504 (1992).

15. Habibagahi, Gh. and Taherian, M. "Prediction of collapse potential for compacted soils using artificial neural networks", Scientia Iranica, 11(12), pp. 1-20 (2004).

16. Zhang, Y., Gallipoli, D., and Augarde, C.E. "Parameter identification for elasto-plastic modelling of unsaturated soils from pressure meter tests by parallel modified particle swarm optimization", Computers and Geotechnics, 48, pp. 293-303 (2013).

17. Saeedi, E., Mahboubi Ardekani, A.R., and Rahami, H. "Determine the critical failure surface in the homogeneous slopes by using the particle swarm optimization algorithm (PSO)", Science Road Journal, 08, pp. 2333 (2014).

18. Jalalvandi, M. and Kashani, A. "Design of reinforcement length in reinforced slope using particle swarm optimization algorithm", International Research Journal of Applied and Basic Sciences, 8(9), pp. 1158-1164 (2014).

19. Kang, F., Xu, Q., and Li, J. "Slope reliability analysis using surrogate models via new support vector machines with swarm intelligence", Applied Mathematical Modelling, 40(11), pp. 6105-6120 (2016).

20. Kang, F., Li, J., and Li, J. "System reliability analysis of slopes using least squares support vector machines with particle swarm optimization", Neurocomputing, 209, pp. 46-56 (2016).

21. Dudley, J.H. "Review of collapsing soils", J. Soil Mech. Found. Div., ASCE, 96(3), pp. 925-947 (1970).

22. Jang, J.-R. "ANFIS: adaptive-network-based fuzzy inference system", in IEEE Transactions on Systems, Man, and Cybernetics, 23(3), pp. 665-685 (May-June 1993). DOI: $10.1109 / 21.256541$

23. Jang, J.-R. and Chuen-Tsai Sun "Neuro-fuzzy modeling and control", in Proceedings of the IEEE, 83(3), pp. 378-406 (March 1995). DOI: 10.1109/5.364486

24. Khademi, F., Jamal, M., Deshpande, N., and Londhe, Sh. "Predicting strength of recycled aggregate concrete using artificial neural network, adaptive neuro-fuzzy inference system and multiple linear regression", International Journal of Sustainable Built Environment, 5(2), pp. 355-369 (2016).

25. Sugeno, M. and Yasukawa, T.A. "fuzzy-logic-based approach to qualitative modeling", IEEE T Fuzzy Syst., 1(1), pp. 7-31 (1993).

26. Takagi, T. and Sugeno, M. "Fuzzy identification of systems and its applications to modeling and control", IEEE Trans Syst. Man Cybern., 15(1), pp. 116-13 (1985).

27. Salagegheh, E., Salagegheh, J., Seyedpoor, S., and Khatibinia, M. "Optimal design of geometrically nonlinear space trusses using an adaptive neuro-fuzzy inference system", Scientia Iranica, Transactions A: Civil Engineering, 16(5), pp. 403-14 (2009).

28. Zeighami, V., Akbari, R., and Ziarati, K. "Development of a method based on particle swarm optimization to solve resource constrained project scheduling problem", Scientia Iranica, 20(6), pp. 2123-2137 (2013).

\section{Appendix A}

Here, the data and their features used in the analysis are represented. Tables A.1, A.2, and A.3 represent 
Table A.1. Training data.

\begin{tabular}{|c|c|c|c|c|c|c|c|}
\hline $\begin{array}{c}\text { Initial dry } \\
\text { unit weight } \\
\left(\mathrm{kN} / \mathrm{m}^{3}\right)\end{array}$ & $\begin{array}{l}\text { Initial water } \\
\text { content }(\%)\end{array}$ & $\begin{array}{c}\text { Pressure at } \\
\text { wetting } \\
(\mathrm{kPa})\end{array}$ & LL (\%) & $\mathrm{Cu}$ & Clay (\%) & Silt (\%) & $\begin{array}{c}\text { Collapse } \\
\text { potential } \\
(\%)\end{array}$ \\
\hline 13.64 & 4.9 & 100 & 22.6 & 16.7 & 12 & 75 & 14.1 \\
\hline 14.72 & 4.9 & 100 & 22.6 & 16.7 & 12 & 75 & 8.1 \\
\hline 15.6 & 4.9 & 100 & 22.6 & 16.7 & 12 & 75 & 4.2 \\
\hline 16.48 & 4.9 & 100 & 22.6 & 16.7 & 12 & 75 & 3.9 \\
\hline 14.62 & 5.3 & 200 & 22.6 & 16.7 & 12 & 75 & 11.6 \\
\hline 15.21 & 5.3 & 200 & 22.6 & 16.7 & 12 & 75 & 8.2 \\
\hline 16.68 & 5.3 & 200 & 22.6 & 16.7 & 12 & 75 & 6.3 \\
\hline 13.44 & 6 & 400 & 22.6 & 16.7 & 12 & 75 & 17.1 \\
\hline 15.3 & 6 & 400 & 22.6 & 16.7 & 12 & 75 & 9 \\
\hline 16.28 & 6 & 400 & 22.6 & 16.7 & 12 & 75 & 6.1 \\
\hline 13.14 & 5.8 & 800 & 22.6 & 16.7 & 12 & 75 & 15.2 \\
\hline 14.42 & 5.8 & 800 & 22.6 & 16.7 & 12 & 75 & 14.6 \\
\hline 16.19 & 5.8 & 800 & 22.6 & 16.7 & 12 & 75 & 9.3 \\
\hline 12.56 & 9.4 & 100 & 22.6 & 16.7 & 12 & 75 & 17.6 \\
\hline 14.91 & 9.4 & 100 & 22.6 & 16.7 & 12 & 75 & 4.5 \\
\hline 16.28 & 9.4 & 100 & 22.6 & 16.7 & 12 & 75 & 1.7 \\
\hline 12.85 & 9.7 & 200 & 22.6 & 16.7 & 12 & 75 & 17.6 \\
\hline 14.62 & 9.7 & 200 & 22.6 & 16.7 & 12 & 75 & 8.7 \\
\hline 15.6 & 9.7 & 200 & 22.6 & 16.7 & 12 & 75 & 3.7 \\
\hline 17.27 & 9.7 & 200 & 22.6 & 16.7 & 12 & 75 & 0.4 \\
\hline 14.52 & 9.3 & 400 & 22.6 & 16.7 & 12 & 75 & 11.4 \\
\hline 15.5 & 9.3 & 400 & 22.6 & 16.7 & 12 & 75 & 6.4 \\
\hline 16.97 & 9.3 & 400 & 22.6 & 16.7 & 12 & 75 & 1 \\
\hline 12.56 & 9.2 & 800 & 22.6 & 16.7 & 12 & 75 & 10.9 \\
\hline 15.6 & 9.2 & 800 & 22.6 & 16.7 & 12 & 75 & 7.7 \\
\hline 16.97 & 9.2 & 800 & 22.6 & 16.7 & 12 & 75 & 4.1 \\
\hline 13.44 & 12.5 & 100 & 22.6 & 16.7 & 12 & 75 & 13.9 \\
\hline 15.6 & 12.5 & 100 & 22.6 & 16.7 & 12 & 75 & 1.9 \\
\hline 18.54 & 12.5 & 100 & 22.6 & 16.7 & 12 & 75 & 0 \\
\hline 13.05 & 11.6 & 200 & 22.6 & 16.7 & 12 & 75 & 14.1 \\
\hline 14.22 & 11.6 & 200 & 22.6 & 16.7 & 12 & 75 & 11.3 \\
\hline 15.6 & 11.6 & 200 & 22.6 & 16.7 & 12 & 75 & 5.5 \\
\hline 12.65 & 12.4 & 400 & 22.6 & 16.7 & 12 & 75 & 11 \\
\hline 14.03 & 12.4 & 400 & 22.6 & 16.7 & 12 & 75 & 11.2 \\
\hline 15.5 & 12.4 & 400 & 22.6 & 16.7 & 12 & 75 & 4.8 \\
\hline 17.07 & 12.4 & 400 & 22.6 & 16.7 & 12 & 75 & 0.4 \\
\hline 14.52 & 12.1 & 800 & 22.6 & 16.7 & 12 & 75 & 7.4 \\
\hline 15.21 & 12.1 & 800 & 22.6 & 16.7 & 12 & 75 & 6.4 \\
\hline 16.97 & 12.1 & 800 & 22.6 & 16.7 & 12 & 75 & 2.4 \\
\hline 14.03 & 15.7 & 100 & 22.6 & 16.7 & 12 & 75 & 10.4 \\
\hline 16.59 & 15.7 & 100 & 22.6 & 16.7 & 12 & 75 & 0.1 \\
\hline 18.44 & 15.7 & 100 & 22.6 & 16.7 & 12 & 75 & 0 \\
\hline 12.65 & 14.6 & 200 & 22.6 & 16.7 & 12 & 75 & 9 \\
\hline
\end{tabular}


Table A.1. Training data (continued).

\begin{tabular}{|c|c|c|c|c|c|c|c|}
\hline $\begin{array}{c}\text { Initial dry } \\
\text { unit weight } \\
\left(\mathrm{kN} / \mathrm{m}^{3}\right)\end{array}$ & $\begin{array}{l}\text { Initial water } \\
\text { content }(\%)\end{array}$ & $\begin{array}{c}\text { Pressure at } \\
\text { wetting } \\
(\mathrm{kPa})\end{array}$ & LL (\%) & $\mathrm{Cu}$ & Clay (\%) & Silt (\%) & $\begin{array}{c}\text { Collapse } \\
\text { potential } \\
(\%)\end{array}$ \\
\hline 13.83 & 14.6 & 200 & 22.6 & 16.7 & 12 & 75 & 9.3 \\
\hline 15.6 & 14.6 & 200 & 22.6 & 16.7 & 12 & 75 & 4.7 \\
\hline 12.75 & 15.6 & 400 & 22.6 & 16.7 & 12 & 75 & 4.6 \\
\hline 13.54 & 15.6 & 400 & 22.6 & 16.7 & 12 & 75 & 4.9 \\
\hline 15.11 & 15.6 & 400 & 22.6 & 16.7 & 12 & 75 & 5.1 \\
\hline 12.66 & 16.3 & 800 & 22.6 & 16.7 & 12 & 75 & 0.6 \\
\hline 13.54 & 16.3 & 800 & 22.6 & 16.7 & 12 & 75 & 1.3 \\
\hline 15.01 & 16.3 & 800 & 22.6 & 16.7 & 12 & 75 & 0.3 \\
\hline 15.89 & 16.3 & 800 & 22.6 & 16.7 & 16 & 75 & 0.2 \\
\hline 14.32 & 5.4 & 100 & 24.2 & 50 & 16 & 52 & 8.2 \\
\hline 15.5 & 5.4 & 100 & 24.2 & 50 & 16 & 52 & 2.1 \\
\hline 16.38 & 5.4 & 100 & 24.2 & 50 & 16 & 52 & 2.9 \\
\hline 13.54 & 6.1 & 200 & 24.2 & 50 & 16 & 52 & 13 \\
\hline 15.31 & 6.1 & 200 & 24.2 & 50 & 16 & 52 & 7.1 \\
\hline 16.09 & 6.1 & 200 & 24.2 & 50 & 16 & 52 & 5.1 \\
\hline 13.73 & 5 & 400 & 24.2 & 50 & 16 & 52 & 14.3 \\
\hline 14.81 & 5 & 400 & 24.2 & 50 & 16 & 52 & 11.2 \\
\hline 16.38 & 5 & 400 & 24.2 & 50 & 16 & 52 & 8.3 \\
\hline 13.73 & 5.5 & 800 & 24.2 & 50 & 16 & 52 & 13.2 \\
\hline 14.72 & 5.5 & 800 & 24.2 & 50 & 16 & 52 & 12.7 \\
\hline 15.3 & 5.5 & 800 & 24.2 & 50 & 16 & 52 & 11.1 \\
\hline 13.15 & 9.2 & 100 & 24.2 & 50 & 16 & 52 & 15 \\
\hline 14.81 & 9.2 & 100 & 24.2 & 50 & 16 & 52 & 5.5 \\
\hline 16.19 & 9.2 & 100 & 24.2 & 50 & 16 & 52 & 0.7 \\
\hline 17.17 & 9.2 & 100 & 24.2 & 50 & 16 & 52 & 0 \\
\hline 15.01 & 9.1 & 200 & 24.2 & 50 & 16 & 52 & 9 \\
\hline 15.99 & 9.1 & 200 & 24.2 & 50 & 16 & 52 & 0.2 \\
\hline 17.27 & 9.1 & 200 & 24.2 & 50 & 16 & 52 & 0.4 \\
\hline 13.54 & 8.4 & 400 & 24.2 & 50 & 16 & 52 & 14.4 \\
\hline 16.38 & 8.4 & 400 & 24.2 & 50 & 16 & 52 & 3.8 \\
\hline 17.27 & 8.4 & 400 & 24.2 & 50 & 16 & 52 & 1.2 \\
\hline 13.64 & 9.1 & 800 & 24.2 & 50 & 16 & 52 & 11.1 \\
\hline 14.62 & 9.1 & 800 & 24.2 & 50 & 16 & 52 & 11.1 \\
\hline 17.17 & 9.1 & 800 & 24.2 & 50 & 16 & 52 & 2.1 \\
\hline 13.15 & 12.4 & 100 & 24.2 & 50 & 16 & 52 & 14.3 \\
\hline 14.62 & 12.4 & 100 & 24.2 & 50 & 16 & 52 & 9.3 \\
\hline 15.6 & 12.4 & 100 & 24.2 & 50 & 16 & 52 & 0 \\
\hline 13.34 & 12.4 & 200 & 24.2 & 50 & 16 & 52 & 10.5 \\
\hline 14.52 & 12.4 & 200 & 24.2 & 50 & 16 & 52 & 5.6 \\
\hline 16.09 & 12.4 & 200 & 24.2 & 50 & 16 & 52 & 1.4 \\
\hline 17.76 & 12.4 & 200 & 24.2 & 50 & 16 & 52 & 0.1 \\
\hline 14.03 & 12.4 & 400 & 24.2 & 50 & 16 & 52 & 9.9 \\
\hline 15.21 & 12.4 & 400 & 24.2 & 50 & 16 & 52 & 6.6 \\
\hline
\end{tabular}


Table A.1. Training data (continued).

\begin{tabular}{|c|c|c|c|c|c|c|c|}
\hline $\begin{array}{c}\text { Initial dry } \\
\text { unit weight } \\
\left(\mathrm{kN} / \mathrm{m}^{3}\right)\end{array}$ & $\begin{array}{l}\text { Initial water } \\
\text { content }(\%)\end{array}$ & $\begin{array}{c}\text { Pressure at } \\
\text { wetting } \\
(\mathrm{kPa})\end{array}$ & LL (\%) & $\mathrm{Cu}$ & Clay (\%) & Silt (\%) & $\begin{array}{c}\text { Collapse } \\
\text { potential } \\
(\%)\end{array}$ \\
\hline 17.46 & 12.4 & 400 & 24.2 & 50 & 16 & 52 & 0.2 \\
\hline 13.05 & 12.4 & 800 & 24.2 & 50 & 16 & 52 & 8.1 \\
\hline 15.99 & 12.4 & 800 & 24.2 & 50 & 16 & 52 & 5.1 \\
\hline 16.87 & 12.4 & 800 & 24.2 & 50 & 16 & 52 & 1.4 \\
\hline 14.13 & 16.9 & 100 & 24.2 & 50 & 16 & 52 & 10.8 \\
\hline 15.03 & 16.9 & 100 & 24.2 & 50 & 16 & 52 & 7 \\
\hline 17.56 & 16.9 & 100 & 24.2 & 50 & 16 & 52 & 0 \\
\hline 13.54 & 16.9 & 200 & 24.2 & 50 & 16 & 52 & 12.4 \\
\hline 14.81 & 16.9 & 200 & 24.2 & 50 & 16 & 52 & 8.9 \\
\hline 16.09 & 16.9 & 200 & 24.2 & 50 & 16 & 52 & 3.4 \\
\hline 13.54 & 16.9 & 400 & 24.2 & 50 & 16 & 52 & 5 \\
\hline 15.21 & 16.9 & 400 & 24.2 & 50 & 16 & 52 & 5.4 \\
\hline 16.28 & 16.9 & 400 & 24.2 & 50 & 16 & 52 & 2.4 \\
\hline 18.05 & 16.9 & 400 & 24.2 & 50 & 16 & 52 & 0 \\
\hline 14.72 & 16.9 & 800 & 0 & 50 & 16 & 52 & 1.3 \\
\hline 16.19 & 16.9 & 800 & 0 & 50 & 16 & 52 & 0.1 \\
\hline 17.76 & 16.9 & 800 & 0 & 35 & 13 & 52 & 0 \\
\hline 14.42 & 6 & 100 & 28.2 & 35 & 13 & 52 & 10.9 \\
\hline 16.28 & 6 & 100 & 28.2 & 35 & 13 & 52 & 2.9 \\
\hline 17.6 & 6 & 100 & 28.2 & 35 & 13 & 52 & 0.8 \\
\hline 14.42 & 6 & 200 & 28.2 & 35 & 13 & 52 & 13.8 \\
\hline 15.6 & 6 & 200 & 28.2 & 35 & 13 & 52 & 8.5 \\
\hline 17.76 & 6 & 200 & 28.2 & 35 & 13 & 52 & 1.7 \\
\hline 14.13 & 6 & 400 & 28.2 & 35 & 13 & 52 & 13.6 \\
\hline 15.21 & 6 & 400 & 28.2 & 35 & 13 & 52 & 12.2 \\
\hline 16.58 & 6 & 400 & 28.2 & 35 & 13 & 52 & 6.2 \\
\hline 14.72 & 6 & 800 & 28.2 & 35 & 13 & 52 & 13 \\
\hline 15.79 & 6 & 800 & 28.2 & 35 & 13 & 52 & 12.6 \\
\hline 16.48 & 6 & 800 & 28.2 & 35 & 13 & 52 & 7 \\
\hline 17.85 & 6 & 800 & 28.2 & 35 & 13 & 52 & 5.4 \\
\hline 15.7 & 9.2 & 100 & 28.2 & 35 & 13 & 52 & 1.8 \\
\hline 17.37 & 9.2 & 100 & 28.2 & 35 & 13 & 52 & 0 \\
\hline 18.93 & 9.2 & 100 & 28.2 & 35 & 13 & 52 & 0 \\
\hline 13.93 & 9.2 & 200 & 28.2 & 35 & 13 & 52 & 13.4 \\
\hline 17.37 & 9.2 & 200 & 28.2 & 35 & 13 & 52 & 0.5 \\
\hline 18.74 & 9.2 & 200 & 28.2 & 35 & 13 & 52 & 0 \\
\hline 13.54 & 9.2 & 400 & 28.2 & 35 & 13 & 52 & 7.4 \\
\hline 15.11 & 9.2 & 400 & 28.2 & 35 & 13 & 52 & 8.4 \\
\hline 17.36 & 9.2 & 400 & 28.2 & 35 & 13 & 52 & 0.9 \\
\hline 14.13 & 9.2 & 800 & 28.2 & 35 & 13 & 52 & 4.5 \\
\hline 15.21 & 9.2 & 800 & 28.2 & 35 & 13 & 52 & 5.3 \\
\hline 15.99 & 9.2 & 800 & 28.2 & 35 & 13 & 52 & 5.5 \\
\hline 14.91 & 12.2 & 100 & 28.2 & 35 & 13 & 52 & 10.1 \\
\hline
\end{tabular}


Table A.1. Training data (continued).

\begin{tabular}{|c|c|c|c|c|c|c|c|}
\hline $\begin{array}{c}\text { Initial dry } \\
\text { unit weight } \\
\left(\mathrm{kN} / \mathrm{m}^{3}\right)\end{array}$ & $\begin{array}{l}\text { Initial water } \\
\text { content }(\%)\end{array}$ & $\begin{array}{c}\text { Pressure at } \\
\text { wetting } \\
(\mathrm{kPa})\end{array}$ & LL (\%) & $\mathrm{Cu}$ & Clay (\%) & Silt (\%) & $\begin{array}{c}\text { Collapse } \\
\text { potential } \\
(\%)\end{array}$ \\
\hline 15.7 & 12.2 & 100 & 28.2 & 35 & 13 & 52 & 6.4 \\
\hline 17.27 & 12.2 & 100 & 28.2 & 35 & 13 & 52 & 0 \\
\hline 18.93 & 12.2 & 100 & 28.2 & 35 & 13 & 52 & 0 \\
\hline 15.79 & 12.2 & 200 & 28.2 & 35 & 13 & 52 & 5.2 \\
\hline 16.78 & 12.2 & 200 & 28.2 & 35 & 13 & 52 & 0 \\
\hline 18.44 & 12.2 & 200 & 28.2 & 35 & 13 & 52 & 0 \\
\hline 14.62 & 12.2 & 400 & 28.2 & 35 & 13 & 52 & 5 \\
\hline 16.87 & 12.2 & 400 & 28.2 & 35 & 13 & 52 & 2 \\
\hline 18.74 & 12.2 & 400 & 28.2 & 35 & 13 & 52 & 0 \\
\hline 14.52 & 12.2 & 800 & 28.2 & 35 & 13 & 52 & 1.5 \\
\hline 15.4 & 12.2 & 800 & 28.2 & 35 & 13 & 52 & 2.3 \\
\hline 18.34 & 12.2 & 800 & 28.2 & 35 & 13 & 52 & 0.3 \\
\hline 15.3 & 15.7 & 100 & 28.2 & 35 & 13 & 52 & 1.7 \\
\hline 16.58 & 15.7 & 100 & 28.2 & 35 & 13 & 52 & 0 \\
\hline 17.17 & 15.7 & 100 & 28.2 & 35 & 13 & 52 & 0 \\
\hline 14.62 & 15.7 & 200 & 28.2 & 35 & 13 & 52 & 0.9 \\
\hline 16.38 & 15.7 & 200 & 28.2 & 35 & 13 & 52 & 0.3 \\
\hline 17.07 & 15.7 & 200 & 28.2 & 35 & 13 & 52 & 0.1 \\
\hline 17.76 & 15.7 & 200 & 28.2 & 35 & 13 & 52 & 0 \\
\hline 15.6 & 15.7 & 400 & 28.2 & 35 & 13 & 52 & 0.1 \\
\hline 16.58 & 15.7 & 400 & 28.2 & 35 & 13 & 52 & 0 \\
\hline 17.46 & 15.7 & 400 & 28.2 & 35 & 13 & 52 & 0 \\
\hline 14.52 & 15.7 & 800 & 28.2 & 35 & 13 & 52 & 0 \\
\hline 17.07 & 15.7 & 800 & 28.2 & 35 & 13 & 52 & 0 \\
\hline 17.66 & 15.7 & 800 & 28.2 & 35 & 13 & 52 & 0 \\
\hline 15 & 4 & 400 & 36.6 & 17.5 & 8.9 & 50.5 & 12.5 \\
\hline 15 & 6 & 400 & 36.6 & 17.5 & 8.9 & 50.5 & 10.1 \\
\hline 15 & 12 & 400 & 36.6 & 17.5 & 8.9 & 50.5 & 11.9 \\
\hline 15 & 16 & 400 & 36.6 & 17.5 & 8.9 & 50.5 & 9.1 \\
\hline 15 & 20 & 400 & 36.6 & 17.5 & 8.9 & 50.5 & 7.5 \\
\hline 13.1 & 6 & 400 & 36.6 & 17.5 & 8.9 & 50.5 & 14.4 \\
\hline 15 & 6 & 400 & 36.6 & 17.5 & 8.9 & 50.5 & 10.2 \\
\hline 15.9 & 6 & 400 & 36.6 & 17.5 & 8.9 & 50.5 & 7.8 \\
\hline 16.8 & 6 & 400 & 36.6 & 17.5 & 8.9 & 50.5 & 4.2 \\
\hline 17.8 & 6 & 400 & 36.6 & 17.5 & 8.9 & 50.5 & 1.3 \\
\hline 15 & 6 & 200 & 36.6 & 17.5 & 8.9 & 50.5 & 7.1 \\
\hline 15 & 6 & 400 & 36.6 & 17.5 & 8.9 & 50.5 & 12.7 \\
\hline 15 & 6 & 800 & 36.6 & 17.5 & 8.9 & 50.5 & 15 \\
\hline 15 & 6 & 1600 & 36.6 & 17.5 & 8.9 & 50.5 & 15.6 \\
\hline 15.4 & 4 & 400 & 29.1 & 25 & 5 & 47.2 & 14.8 \\
\hline 15.4 & 6 & 400 & 29.1 & 25 & 5 & 47.2 & 13.3 \\
\hline 15.4 & 8 & 400 & 29.1 & 25 & 5 & 47.2 & 11.7 \\
\hline 15.4 & 12 & 400 & 29.1 & 25 & 5 & 47.2 & 8.7 \\
\hline
\end{tabular}


Table A.1. Training data (continued).

\begin{tabular}{|c|c|c|c|c|c|c|c|}
\hline $\begin{array}{c}\text { Initial dry } \\
\text { unit weight } \\
\left(\mathrm{kN} / \mathrm{m}^{\mathbf{3}}\right)\end{array}$ & $\begin{array}{l}\text { Initial water } \\
\text { content }(\%)\end{array}$ & $\begin{array}{c}\text { Pressure at } \\
\text { wetting } \\
(\mathrm{kPa})\end{array}$ & LL (\%) & $\mathrm{Cu}$ & Clay (\%) & Silt (\%) & $\begin{array}{c}\text { Collapse } \\
\text { potential } \\
(\%)\end{array}$ \\
\hline 15.4 & 20 & 400 & 29.1 & 25 & 5 & 47.2 & 0.1 \\
\hline 13.5 & 6 & 400 & 29.1 & 25 & 5 & 47.2 & 21.3 \\
\hline 14.5 & 6 & 400 & 29.1 & 25 & 5 & 47.2 & 18.7 \\
\hline 15.4 & 6 & 400 & 29.1 & 25 & 5 & 47.2 & 13.6 \\
\hline 17.4 & 6 & 400 & 29.1 & 25 & 5 & 47.2 & 6 \\
\hline 18.3 & 6 & 400 & 29.1 & 25 & 5 & 47.2 & 1 \\
\hline 19.3 & 6 & 400 & 29.1 & 25 & 5 & 47.2 & 0 \\
\hline 15.4 & 6 & 200 & 29.1 & 25 & 5 & 47.2 & 8.5 \\
\hline 15.4 & 6 & 800 & 29.1 & 25 & 5 & 47.2 & 14.7 \\
\hline 15.4 & 6 & 1200 & 29.1 & 25 & 5 & 47.2 & 17.5 \\
\hline 15.4 & 6 & 3600 & 29.1 & 25 & 5 & 47.2 & 17.9 \\
\hline 13.6 & 4 & 400 & 57.2 & 60 & 13.2 & 73.5 & 19.2 \\
\hline 13.6 & 8 & 400 & 57.2 & 60 & 13.2 & 73.5 & 16.2 \\
\hline 13.6 & 12 & 400 & 57.2 & 60 & 13.2 & 73.5 & 15 \\
\hline 13.6 & 16 & 400 & 57.2 & 60 & 13.2 & 73.5 & 13.2 \\
\hline 13.6 & 20 & 400 & 57.2 & 60 & 13.2 & 73.5 & 12 \\
\hline 12.8 & 6 & 400 & 57.2 & 60 & 13.2 & 73.5 & 20 \\
\hline 13.6 & 6 & 400 & 57.2 & 60 & 13.2 & 73.5 & 17.5 \\
\hline 14.5 & 6 & 400 & 57.2 & 60 & 13.2 & 73.5 & 9.5 \\
\hline 15.3 & 6 & 400 & 57.2 & 60 & 13.2 & 73.5 & 6.3 \\
\hline 17 & 6 & 400 & 57.2 & 60 & 13.2 & 73.5 & 0.1 \\
\hline 13.6 & 6 & 200 & 57.2 & 60 & 13.2 & 73.5 & 12 \\
\hline 13.6 & 6 & 400 & 57.2 & 60 & 13.2 & 73.5 & 17.5 \\
\hline 13.6 & 6 & 800 & 57.2 & 60 & 13.2 & 73.5 & 19 \\
\hline 13.6 & 6 & 3200 & 57.2 & 60 & 13.2 & 73.5 & 21.9 \\
\hline 13.8 & 4 & 400 & 28 & 11.5 & 10 & 70.4 & 16.8 \\
\hline 13.8 & 8 & 400 & 28 & 11.5 & 10 & 70.4 & 15.1 \\
\hline 13.8 & 12 & 400 & 28 & 11.5 & 10 & 70.4 & 14.3 \\
\hline 13.8 & 20 & 400 & 28 & 11.5 & 10 & 70.4 & 9.7 \\
\hline 12 & 6 & 400 & 28 & 11.5 & 10 & 70.4 & 21.3 \\
\hline 12.9 & 6 & 400 & 28 & 11.5 & 10 & 70.4 & 19.5 \\
\hline 14.6 & 6 & 400 & 28 & 11.5 & 10 & 70.4 & 12 \\
\hline 15.5 & 6 & 400 & 28 & 11.5 & 10 & 70.4 & 7.5 \\
\hline 16.3 & 6 & 400 & 28 & 11.5 & 10 & 70.4 & 0.2 \\
\hline 17.2 & 6 & 400 & 28 & 11.5 & 10 & 70.4 & 3.7 \\
\hline 13.8 & 6 & 400 & 28 & 11.5 & 10 & 70.4 & 16.5 \\
\hline 13.8 & 6 & 800 & 28 & 11.5 & 10 & 70.4 & 15.1 \\
\hline 13.8 & 6 & 1600 & 28 & 11.5 & 10 & 70.4 & 20.8 \\
\hline 13.8 & 6 & 3200 & 28 & 11.5 & 10 & 70.4 & 3 \\
\hline 13 & 6 & 400 & 36 & 35 & 26 & 49.6 & 21.1 \\
\hline 13 & 8 & 400 & 36 & 35 & 26 & 49.6 & 19.3 \\
\hline 13 & 12 & 400 & 36 & 35 & 26 & 49.6 & 19.2 \\
\hline 13 & 16 & 400 & 36 & 35 & 26 & 49.6 & 14.9 \\
\hline
\end{tabular}


Table A.1. Training data (continued).

\begin{tabular}{|c|c|c|c|c|c|c|c|}
\hline $\begin{array}{c}\text { Initial dry } \\
\text { unit weight } \\
\left(\mathrm{kN} / \mathrm{m}^{\mathbf{3}}\right)\end{array}$ & $\begin{array}{l}\text { Initial water } \\
\text { content }(\%)\end{array}$ & $\begin{array}{c}\text { Pressure at } \\
\text { wetting } \\
(\mathrm{kPa})\end{array}$ & LL (\%) & $\mathrm{Cu}$ & Clay (\%) & Silt (\%) & $\begin{array}{c}\text { Collapse } \\
\text { potential } \\
(\%)\end{array}$ \\
\hline 11.4 & 6 & 400 & 36 & 35 & 26 & 49.6 & 23.2 \\
\hline 12.2 & 6 & 400 & 36 & 35 & 26 & 49.6 & 24.1 \\
\hline 13 & 6 & 400 & 36 & 35 & 26 & 49.6 & 22.2 \\
\hline 13.9 & 6 & 400 & 36 & 35 & 26 & 49.6 & 16.1 \\
\hline 15.5 & 6 & 400 & 36 & 35 & 26 & 49.6 & 11.9 \\
\hline 13 & 6 & 200 & 36 & 35 & 26 & 49.6 & 17 \\
\hline 13 & 6 & 400 & 36 & 35 & 26 & 49.6 & 22 \\
\hline 13 & 6 & 1600 & 36 & 35 & 26 & 49.6 & 23.2 \\
\hline 13 & 6 & 3200 & 36 & 35 & 26 & 49.6 & 24.5 \\
\hline 14.6 & 4 & 400 & 28.2 & 100 & 15 & 42.9 & 24.5 \\
\hline 14.6 & 6 & 400 & 28.2 & 100 & 15 & 42.9 & 22.5 \\
\hline 14.6 & 12 & 400 & 28.2 & 100 & 15 & 42.9 & 16.3 \\
\hline 14.6 & 16 & 400 & 28.2 & 100 & 15 & 42.9 & 16 \\
\hline 14.6 & 20 & 400 & 28.2 & 100 & 15 & 42.9 & 14 \\
\hline 12.8 & 6 & 400 & 28.2 & 100 & 15 & 42.9 & 26.4 \\
\hline 14.6 & 6 & 400 & 28.2 & 100 & 15 & 42.9 & 20.2 \\
\hline 15.6 & 6 & 400 & 28.2 & 100 & 15 & 42.9 & 16.5 \\
\hline 16.5 & 6 & 400 & 28.2 & 100 & 15 & 42.9 & 16.1 \\
\hline 17.4 & 6 & 400 & 28.2 & 100 & 15 & 42.9 & 9.4 \\
\hline 14.6 & 6 & 200 & 28.2 & 100 & 15 & 42.9 & 14.9 \\
\hline 14.6 & 6 & 400 & 28.2 & 100 & 15 & 42.9 & 19.9 \\
\hline 14.6 & 6 & 800 & 28.2 & 100 & 15 & 42.9 & 23 \\
\hline 14.6 & 6 & 1600 & 28.2 & 100 & 15 & 42.9 & 25.7 \\
\hline 18.2 & 6 & 200 & 30 & 6.4 & 9 & 7 & 0 \\
\hline 18.2 & 6 & 400 & 30 & 6.4 & 9 & 7 & 0.1 \\
\hline 18.2 & 6 & 800 & 30 & 6.4 & 9 & 7 & 0.1 \\
\hline 18.2 & 6 & 1600 & 30 & 6.4 & 9 & 7 & 1.5 \\
\hline 18.2 & 3 & 400 & 30 & 6.4 & 9 & 7 & 1.2 \\
\hline 18.2 & 6 & 400 & 30 & 6.4 & 9 & 7 & 0 \\
\hline 18.2 & 9 & 400 & 30 & 6.4 & 9 & 7 & 0 \\
\hline 15.7 & 6 & 400 & 30 & 6.4 & 9 & 7 & 6.6 \\
\hline 16.3 & 6 & 400 & 30 & 6.4 & 9 & 7 & 4.3 \\
\hline 17.7 & 6 & 400 & 30 & 6.4 & 9 & 7 & 1 \\
\hline 18.2 & 6 & 400 & 30 & 6.4 & 9 & 7 & 0 \\
\hline 16.9 & 6 & 200 & 25 & 3.4 & 2 & 5.8 & 0 \\
\hline 16.9 & 6 & 400 & 25 & 3.4 & 2 & 5.8 & 0.9 \\
\hline 16.9 & 6 & 800 & 25 & 3.4 & 2 & 5.8 & 2.1 \\
\hline 16.9 & 6 & 1600 & 25 & 3.4 & 2 & 5.8 & 3.1 \\
\hline 16.9 & 0 & 400 & 25 & 3.4 & 2 & 5.8 & 2.7 \\
\hline 16.9 & 3 & 400 & 25 & 3.4 & 2 & 5.8 & 1 \\
\hline 16.9 & 6 & 400 & 25 & 3.4 & 2 & 5.8 & 0.5 \\
\hline 16.9 & 9 & 400 & 25 & 3.4 & 2 & 5.8 & 0 \\
\hline 14.6 & 6 & 400 & 25 & 3.4 & 2 & 5.8 & 6 \\
\hline
\end{tabular}


Table A.1. Training data (continued).

\begin{tabular}{cccccccc}
\hline $\begin{array}{c}\text { Initial dry } \\
\text { unit weight } \\
\left(\mathbf{k N} / \mathbf{m}^{\mathbf{3}}\right)\end{array}$ & $\begin{array}{c}\text { Initial water } \\
\text { content (\%) }\end{array}$ & $\begin{array}{c}\text { Pressure at } \\
\text { wetting } \\
\mathbf{( k P a )}\end{array}$ & LL (\%) & $\mathbf{C u}$ & Clay (\%) & Silt (\%) & $\begin{array}{c}\text { Collapse } \\
\text { potential } \\
(\%)\end{array}$ \\
\hline 15.1 & 6 & 400 & 25 & 3.4 & 2 & 5.8 & 5.1 \\
16.4 & 6 & 400 & 25 & 3.4 & 2 & 5.8 & 2.1 \\
16.9 & 6 & 400 & 25 & 3.4 & 2 & 5.8 & 1 \\
\hline
\end{tabular}

Table A.2. Testing data.

\begin{tabular}{|c|c|c|c|c|c|c|c|}
\hline $\begin{array}{c}\text { Initial dry } \\
\text { unit weight } \\
\left(\mathrm{kN} / \mathrm{m}^{3}\right)\end{array}$ & $\begin{array}{l}\text { Initial water } \\
\text { content }(\%)\end{array}$ & $\begin{array}{c}\text { Pressure at } \\
\text { wetting } \\
(\mathrm{kPa})\end{array}$ & LL (\%) & $\mathrm{Cu}$ & Clay (\%) & Silt (\%) & $\begin{array}{c}\text { Collapse } \\
\text { potential } \\
(\%)\end{array}$ \\
\hline 13.15 & 5.3 & 200 & 22.6 & 16.7 & 12 & 75 & 17.3 \\
\hline 14.32 & 6 & 400 & 22.6 & 16.7 & 12 & 75 & 13.5 \\
\hline 15.6 & 5.8 & 800 & 22.6 & 16.7 & 12 & 75 & 11.3 \\
\hline 17.46 & 9.4 & 100 & 22.6 & 16.7 & 12 & 75 & 0 \\
\hline 12.56 & 9.3 & 400 & 22.6 & 16.7 & 12 & 75 & 11.2 \\
\hline 14.32 & 9.2 & 800 & 22.6 & 16.7 & 12 & 75 & 13.3 \\
\hline 16.38 & 12.5 & 100 & 22.6 & 16.7 & 12 & 75 & 0.2 \\
\hline 17.17 & 11.6 & 200 & 22.6 & 16.7 & 12 & 75 & 0.3 \\
\hline 12.85 & 12.1 & 800 & 22.6 & 16.7 & 12 & 75 & 5.6 \\
\hline 15.01 & 15.7 & 100 & 22.6 & 16.7 & 12 & 75 & 5.2 \\
\hline 14.91 & 14.6 & 200 & 22.6 & 16.7 & 12 & 75 & 7.4 \\
\hline 15.7 & 15.6 & 400 & 22.6 & 16.7 & 12 & 75 & 4.5 \\
\hline 13.54 & 5.4 & 100 & 24.2 & 50 & 16 & 52 & 10.4 \\
\hline 14.32 & 6.1 & 200 & 24.2 & 50 & 16 & 52 & 10 \\
\hline 15.6 & 5 & 400 & 24.2 & 50 & 16 & 52 & 8.4 \\
\hline 16.09 & 5.5 & 800 & 24.2 & 50 & 16 & 52 & 12.5 \\
\hline 13.54 & 9.1 & 200 & 24.2 & 50 & 16 & 52 & 15 \\
\hline 14.81 & 8.4 & 400 & 24.2 & 50 & 16 & 52 & 11.4 \\
\hline 15.7 & 9.1 & 800 & 24.2 & 50 & 16 & 52 & 8 \\
\hline 17.76 & 12.4 & 100 & 24.2 & 50 & 16 & 52 & 0.1 \\
\hline 13.44 & 12.4 & 400 & 24.2 & 50 & 16 & 52 & 10.1 \\
\hline 14.22 & 12.4 & 800 & 24.2 & 50 & 16 & 52 & 9.1 \\
\hline 15.99 & 16.9 & 100 & 24.2 & 50 & 16 & 52 & 1.1 \\
\hline 17.56 & 16.9 & 200 & 24.2 & 50 & 16 & 52 & 0 \\
\hline 13.83 & 16.9 & 800 & 24.2 & 50 & 16 & 52 & 0.1 \\
\hline 15.6 & 6 & 100 & 28.2 & 35 & 13 & 52 & 6.8 \\
\hline 16.58 & 6 & 200 & 28.2 & 35 & 13 & 52 & 4.3 \\
\hline 17.66 & 6 & 400 & 28.2 & 35 & 13 & 52 & 2.6 \\
\hline 14.22 & 9.2 & 100 & 28.2 & 35 & 13 & 52 & 4.7 \\
\hline 15.99 & 9.2 & 200 & 28.2 & 35 & 13 & 52 & 5.4 \\
\hline 16.38 & 9.2 & 400 & 28.2 & 35 & 13 & 52 & 5.6 \\
\hline 17.17 & 9.2 & 800 & 28.2 & 35 & 13 & 52 & 3.3 \\
\hline 14.52 & 12.2 & 200 & 28.2 & 35 & 13 & 52 & 5.5 \\
\hline 15.7 & 12.2 & 400 & 28.2 & 35 & 13 & 52 & 3.6 \\
\hline 16.97 & 12.2 & 800 & 28.2 & 35 & 13 & 52 & 2.3 \\
\hline
\end{tabular}


Table A.2. Testing data (continued).

\begin{tabular}{|c|c|c|c|c|c|c|c|}
\hline $\begin{array}{c}\text { Initial dry } \\
\text { unit weight } \\
\left(\mathrm{kN} / \mathrm{m}^{3}\right)\end{array}$ & $\begin{array}{l}\text { Initial water } \\
\text { content }(\%)\end{array}$ & $\begin{array}{c}\text { Pressure at } \\
\text { wetting } \\
(\mathrm{kPa})\end{array}$ & LL (\%) & $\mathrm{Cu}$ & Clay (\%) & Silt (\%) & $\begin{array}{c}\text { Collapse } \\
\text { potential } \\
(\%) \\
\end{array}$ \\
\hline 17.85 & 15.7 & 100 & 28.2 & 35 & 13 & 52 & 0 \\
\hline 14.72 & 15.7 & 400 & 28.2 & 35 & 13 & 52 & 0.1 \\
\hline 15.89 & 15.7 & 800 & 28.2 & 35 & 13 & 52 & 0 \\
\hline 15 & 8 & 400 & 36.6 & 17.5 & 8.9 & 50.5 & 12.5 \\
\hline 14 & 6 & 400 & 36.6 & 17.5 & 8.9 & 50.5 & 13.2 \\
\hline 18.7 & 6 & 400 & 36.6 & 17.5 & 8.9 & 50.5 & 0 \\
\hline 15 & 6 & 3200 & 36.6 & 17.5 & 8.9 & 50.5 & 15.8 \\
\hline 15.4 & 16 & 400 & 29.1 & 25 & 5 & 47.2 & 5 \\
\hline 16.4 & 6 & 400 & 29.1 & 25 & 5 & 47.2 & 9.6 \\
\hline 15.4 & 6 & 400 & 29.1 & 25 & 5 & 47.2 & 13.6 \\
\hline 13.6 & 6 & 400 & 57.2 & 60 & 13.2 & 73.5 & 17.5 \\
\hline 11.9 & 6 & 400 & 57.2 & 60 & 13.2 & 73.5 & 22.7 \\
\hline 16.2 & 6 & 400 & 57.2 & 60 & 13.2 & 73.5 & 3.3 \\
\hline 13.6 & 6 & 1600 & 57.2 & 60 & 13.2 & 73.5 & 21.6 \\
\hline 13.8 & 16 & 400 & 28 & 11.5 & 10 & 70.4 & 7 \\
\hline 13.8 & 6 & 400 & 28 & 11.5 & 10 & 70.4 & 16.6 \\
\hline 13.8 & 6 & 200 & 28 & 11.5 & 10 & 70.4 & 12 \\
\hline 13 & 4 & 400 & 36 & 35 & 26 & 49.6 & 22.6 \\
\hline 13 & 20 & 400 & 36 & 35 & 26 & 49.6 & 11 \\
\hline 14.7 & 6 & 400 & 36 & 35 & 26 & 49.6 & 15.8 \\
\hline 13 & 6 & 800 & 36 & 35 & 26 & 49.6 & 21.2 \\
\hline 14.6 & 8 & 400 & 28.2 & 100 & 15 & 42.9 & 18.6 \\
\hline 13.7 & 6 & 400 & 28.2 & 100 & 15 & 42.9 & 25.1 \\
\hline 18.3 & 6 & 400 & 28.2 & 100 & 15 & 42.9 & 9 \\
\hline 14.6 & 6 & 3200 & 28.2 & 100 & 15 & 42.9 & 26.4 \\
\hline 18.2 & 6 & 3200 & 30 & 6.4 & 9 & 7 & 4.2 \\
\hline 18.2 & 12 & 400 & 30 & 6.4 & 9 & 7 & 0 \\
\hline 19.2 & 6 & 400 & 30 & 6.4 & 9 & 7 & 0 \\
\hline 16.9 & 6 & 3200 & 25 & 3.4 & 2 & 5.8 & 6.5 \\
\hline 16.9 & 12 & 400 & 25 & 3.4 & 2 & 5.8 & 0 \\
\hline 17.8 & 6 & 400 & 25 & 3.4 & 2 & 5.8 & 0 \\
\hline
\end{tabular}

Table A.3. Range of effective parameters.

\begin{tabular}{cccccccc}
\hline & $\begin{array}{c}\text { Initial dry } \\
\text { unit weight } \\
\left(\mathbf{k N} / \mathbf{m}^{\mathbf{3}}\right)\end{array}$ & $\begin{array}{c}\text { Initial water } \\
\text { content (\%) }\end{array}$ & $\begin{array}{c}\text { Pressure at } \\
\text { wetting } \\
\mathbf{( k P a )}\end{array}$ & $\mathbf{L L ~ ( \% )}$ & $\mathbf{C u}$ & Clay (\%) & Silt (\%) \\
\hline MAX & 19.3 & 20 & 3600 & 57.2 & 100 & 26 & 75 \\
MIN & 11.4 & 0 & 100 & 0 & 3.4 & 2 & 5.8 \\
\hline
\end{tabular}

training data, test data and range of effective parameters, respectively.

\section{Biographies}

Mohammad Mehdi Hasheminejad was born in Isfahan, Iran, in 1988. He received the BS degree in Civil
Engineering from the University of Isfahan, Isfahan, Iran, in 2011, and the MSc degree in Geotechnical Engineering from the Isfahan University of Technology (IUT), Isfahan, Iran in 2013. He is a PhD Student in Geotechnical Engineering at Islamic Azad University of Najafabad (IAUN), Isfahan, Iran. His current research interests include ground response analysis, liquefaction, 
soil dynamic, numerical modeling, and optimization methods in geotechnical en gineering.

Nasrin Sohankar was born in Isfahan, Iran in 1988. He received the BS degree in Civil Engineering from the University of Isfahan, Isfahan, Iran in 2011, and the MSc degree in Structural Engineering from the Isfahan University of Technology (IUT), Isfahan, Iran in 2013. She is a PhD Student in Structural Engineering at Islamic Azad University of Najafabad (IAUN), Isfahan, Iran. Her current research interests include post buckling response of Functionally Graded Material (FGM) plate, optimization method and damage analysis of structure.
Alborz Hajiannia received the BS degree from Isfahan University of Technology (IUT), Isfahan, Iran in 1997, and also obtained $\mathrm{MSc}$ and $\mathrm{PhD}$ degrees in Geotechnical Engineering from the Amirkabir University of Technology (AUT), Tehran, Iran in 1999 and 2011, respectively. He is currently an Assistant Professor of Civil Engineering Department at Islamic Azad University of Najafabad (IAUN). His research interests lie in the soil stabilization and improvement, tunneling engineering, soil dam design, numerical modelling and soil dynamic. $\mathrm{He}$ has published over 50 research articles on related subjects, including soil stabilization and numerical modelling. 